【論文】

\title{
変厚矩形板の曲げの一解析法

\author{
BENDING ANALYSIS OF RECTANGULAR PLATES \\ WITH VARIABLE THICKNESS
}

\author{
崎山毅* ・松田浩** \\ By Takeshi SAKIYAMA and Hiroshi MATSUDA
}

\section{1. 序雼}

変厚矩形板の基礎微分方程式は, 任意の関数として与 えられる板剛度および板厚を係数とする，いわゆる変数 係数の連立偏微分方程式となるために, その解析解を一 般的に求めることはほとんど不可能であると考えられ る. そのため, 変厚板の解法としていくつかの近似解 法, 数值解法が提案されてきている.

梶田・成岡 ${ }^{1}$ は, 一方向に断面の厚さが線形に変化す る場合の剛性マトリックスを誘導し，これを用いて，有 限要素法で等分布荷重を満載する变厚片持板のたわみお よび曲げモーメントを解析した。倉田・谷平 ${ }^{2}$ は，任意 の変厚四辺形板の曲げ問題について, 解析的近似解法を 提案し, 変断面形状が板剛度として 2 回微分可能な関数 形で与えられるならば，変厚板でも等厚板と本質的に同 じ方法で解くことができることを示し，たわみおよび曲 げモーメントの計算を行った.

一方, 四辺単純支持という限られた境界条件をもつ変 厚矩形板に関しては, いくつかの場合について, 理論解 が求められている. 中川棌は, 曲げ剛性が $x, y$ の 1 次 関数で表わされる変厚矩形板について,たわみ影響面の 理論解を求めた。 また, Fan Jia-rang() は, 曲げ棡性が 一方向に線形に変化する変厚矩形板について, 部分分布 荷重および集中荷重に対するたわみおよび曲げモーメン トの理論解を求めた.

さらに, 久保・吉田 ${ }^{5}$ は, 任意形状の平板の曲げ問題 について, 有限要素法と差分法との接点に位置する数值 解析法を提案し, その応用として, 板厚が徐々に変化す る変厚板について, かなりの精度の解を得ることができ ることを示した.

以上のように, 変厚矩形板の曲げ問題について, 多く

* 正会員 工博 長崎大学助教授 工学部構造工学科

** 正会員 工修 長崎大学助手 工学部構造工学科
の研究が行われてきているが，任意の境界条件，荷重条 件, および, 変断面性に対する解析の容易さおよび方法 の一般性という観点に立てば, 変厚矩形板の解法に関し てまだ検討の余地が残されているものと考えられる.

本論文は, 変厚矩形板を基礎微分方程式に基ついて直 接的に解析できる解法の確立を目的としたものである. 基礎微分方程式の積分方程式への変換と積分方程式の近 似解法の応用とにより, 変厚矩形板の基礎微分方程式の 解析的近似解を求め, これに基づく変厚板の解法を提示 した. 本解法によれば, 任意の境界条件および荷重条件 をもつ変厚矩形板を一般的に解析することができる.ま た，板剛度や板厚の変化が不規則で関数表示できない場 合についても, 矩形板の縦横の等分割線の交点における 板剛度, 板厚の值が与えられれば,これらが規則的な場 合と同様に解析することができる.

\section{2. 変厚板の基礎微分方程式}

平板のせん断力を $Q_{y}, Q_{x}$, ねじりモーメントを $M_{x y}$, 曲げモーメントを $M_{y}, M_{x}$ ，たわみ角を $\theta_{y}, \theta_{x}$ ，たわ みをwとすれば, 変厚板を含む一般的な矩形板の曲げ に関する 基䃈微分方程式は, Reissner の平板曲げ理論 に基づいて, 次の連立偏微分方程式となる.

$$
\begin{aligned}
& \frac{\partial Q_{x}}{\partial x}+\frac{\partial Q_{y}}{\partial y}+q=0 \cdots \cdots \cdots \cdots \cdots \cdots \cdots \cdots \cdots \cdots \cdots \cdots \cdots \cdots \cdots(1 \cdot \mathrm{a}) \\
& \frac{\partial M_{x}}{\partial x}+\frac{\partial M_{x y}}{\partial y}-Q_{x}=0 \cdots \cdots \cdots \cdots \cdots \cdots \cdots(1 \cdot \mathrm{b}) \\
& \frac{\partial M_{y}}{\partial y}+\frac{\partial M_{x y}}{\partial x}-Q_{y}=0 \ldots \ldots \ldots \ldots \ldots \ldots \ldots(1 \cdot \mathrm{c}) \\
& \frac{\partial \theta_{x}}{\partial x}+\nu \frac{\partial \theta_{y}}{\partial y}=\frac{M_{x}}{D} \cdots \cdots \cdots \cdots \cdots \cdots \cdots \cdots \cdots(1 \cdot \mathrm{d}) \\
& \frac{\partial \theta_{y}}{\partial y}+\nu \frac{\partial \theta_{x}}{\partial x}=\frac{M_{y}}{D} \cdots \cdots \cdots \cdots \cdots \cdots \cdots \cdots \cdots(1 \cdot \mathrm{e}) \\
& \frac{\partial \theta_{x}}{\partial y}+\frac{\partial \theta_{y}}{\partial x}=\frac{2}{D(1-\nu)} M_{x y} \cdots \cdots \cdots \cdots \cdots(1 \cdot \mathrm{f})
\end{aligned}
$$




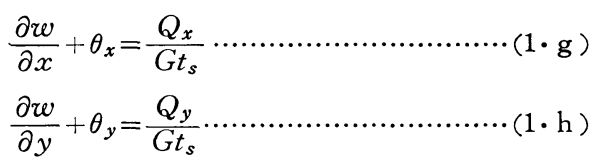

ここに, $q=q(x, y):$ 横荷重強度, $E:$ 弾性係数

$G:$ せん断弾性係数, レ: ポアソン比

$D=\frac{E h^{3}}{12\left(1-\nu^{2}\right)}:$ 板剛度, $t_{s}=\frac{h}{1.2}$

$h=h(x, y)$ : 板厚

ここで, 断面力 $Q_{y}, Q_{x}, M_{x y}, M_{y}, M_{x}$ および変形 $\theta_{y}, \theta_{x}, w$ に関して, 次の無次元量 $X_{1} \sim X_{8}$,

$$
\begin{aligned}
& X_{1}=\frac{a^{2}}{D_{0}\left(1-\nu^{2}\right)} Q_{y}, X_{2}=\frac{a^{2}}{D_{0}\left(1-\nu^{2}\right)} Q_{x} \\
& X_{3}=\frac{a}{D_{0}\left(1-\nu^{2}\right)} M_{x y}, X_{4}=\frac{a}{D_{0}\left(1-\nu^{2}\right)} M_{y} \\
& X_{5}=\frac{a}{D_{0}\left(1-\nu^{2}\right)} M_{x}, X_{6}=\theta_{y}, X_{7}=\theta_{x}, X_{8}=w / a
\end{aligned}
$$

を導入すれば，式 $(1 \cdot a) 〜(1 \cdot h)$ は次のように書き換え られる。

$$
\begin{aligned}
& \frac{\partial X_{1}}{\partial \zeta}+\mu \frac{\partial X_{2}}{\partial \eta}=-\bar{q} \cdots \\
& \frac{\partial X_{3}}{\partial \zeta}+\mu \frac{\partial X_{5}}{\partial \eta}=\mu X_{2} \cdots \\
& \frac{\partial X_{4}}{\partial \zeta}+\mu \frac{\partial X_{3}}{\partial \eta}=\mu X_{1} \cdots \\
& \frac{\partial X_{6}}{\partial \zeta}+\nu \mu \frac{\partial X_{7}}{\partial \eta}=I X_{4} \\
& \nu \frac{\partial X_{6}}{\partial \zeta}+\mu \frac{\partial X_{7}}{\partial \eta}=I X_{5} \\
& \frac{\partial X_{7}}{\partial \zeta}+\mu \frac{\partial X_{6}}{\partial \eta}=J X_{3} \cdots \\
& \frac{\partial X_{8}}{\partial \eta}+X_{7}=\kappa X_{2} \cdots \cdots . \\
& \frac{\partial X_{8}}{\partial \zeta}+\mu X_{6}=\mu \kappa X_{1} \cdots
\end{aligned}
$$

ここに, $x=a \eta, y=b \zeta$

$a, b:$ 矩形板の横, 綐の辺長

$\mu=\frac{b}{a}, \quad \bar{q}=\mu k^{2} \frac{q}{q_{0}}, \quad k^{2}=\frac{q_{0} a^{3}}{D_{0}\left(1-\nu^{2}\right)}$

$q_{0}:$ 基準荷重強度

$I=\mu\left(1-\nu^{2}\right)\left(\frac{h_{0}}{h}\right)^{3}, J=2 \mu(1+\nu)\left(\frac{h_{0}}{h}\right)^{3}$

$h_{0}$ : 基準板厚

$\kappa=\frac{1}{10} \frac{E}{G}\left(\frac{h_{0}}{a}\right)^{2} \frac{h_{0}}{h}$

$D_{0}=\frac{E h_{0}{ }^{3}}{12\left(1-\nu^{2}\right)}:$ 基準板剛度

式 $(2 \cdot a) \sim(2 \cdot h)$ を用いて, 分布荷重や集中荷重など の任意の横荷重を受け, 任意の境界条件をもつ, 変厚矩 形板の曲げ解析が行われる.

\section{3. 基礎微分方程式の近似解}

任意の変厚矩形板に関して, 任意の荷重条件および境 界条件のもとで, 基礎微分方程式 $(2 \cdot \mathrm{a}) \sim(2 \cdot \mathrm{h})$ の解析 解を一般的に得ることはほとんど不可能であると考えら れるので, ここでは, Fig. 1 に示すような, 矩形板の 縦横の等分割線の交点を対象として, これらの離散点に おける, 基礎微分方程式の近似解を求めることとする。

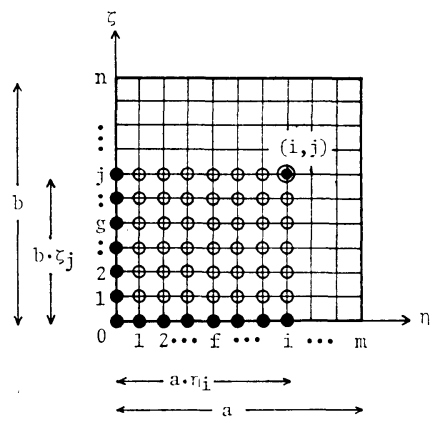

Fig. 1 Discrete Points on Rectangular Plate.

Fig. 1 に示すように, 矩形板を横, 縦方向にそれぞ れ $m, n$ 等分し, これらの等分割線の交点の集合体と みなす.ここで, 任意の交点 $(i, j)$ に関連する矩形領 域, $0 \leqslant \eta \leqslant \eta_{i}, 0 \leqslant \zeta \leqslant \zeta_{j}$ に注目し，これを領域 $[i$, $j]$ と表記することとする．また，○印を付けた交点 $(i$,

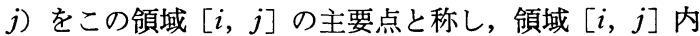
の主要点以外の 交点 $(f, g), f=0,1, \cdots, i, g=0,1$, $\cdots, j$ をこの領域の従属点と称することとする．さらに， 従属点に関しては, $\eta=0$ および $\zeta=0$ の境界辺上にあ るの印を付けた交点 $(f, 0)$ および $(0, g)$ を境界従属 点と称し, その他の○印を付けた交点 $(f, g)$ を内部従 属点と称して区別することとする.

はじめに, 基礎微分方程式 $(2 \cdot a) \sim(2 \cdot h)$ の各式を領 域 $[i, j]$ において面積分し, 積分方程式に変換すれば, 次の諸式が得られる.

$$
\begin{aligned}
& \int_{0}^{\eta_{i}} X_{1}\left(\eta, \zeta_{j}\right) d \eta+\mu \int_{0}^{\zeta_{j}} X_{2}\left(\eta_{i}, \zeta\right) d \zeta \\
& =\int_{0}^{\eta_{i}} X_{1}(\eta, 0) d \eta+\mu \int_{0}^{\zeta_{j}} X_{2}(0, \zeta) d \zeta-\int_{0}^{\zeta_{j}} \int_{0}^{\eta_{i}} \bar{q} d \eta d \zeta \\
& \int_{0}^{\eta_{i}} X_{3}\left(\eta, \zeta_{j}\right) d \eta+\mu \int_{0}^{\zeta_{j}} X_{5}\left(\eta_{i}, \zeta\right) d \zeta \\
& =\int_{0}^{\eta_{i}} X_{3}(\eta, 0) d \eta+\mu \int_{0}^{\zeta_{j}} X_{5}(0, \zeta) d \zeta \\
& +\mu \int_{0}^{\zeta_{j}} \int_{0}^{\eta_{i}} X_{2} d \eta d \zeta
\end{aligned}
$$

$\int_{0}^{\zeta_{j}} X_{8}\left(\eta_{i}, \zeta\right) d \zeta$

$$
=\int_{0}^{\zeta_{j}} X_{8}(0, \zeta) d \zeta+\int_{0}^{\zeta_{j}} \int_{0}^{\eta_{i}}\left(\kappa X_{2}-X_{7}\right) d \eta d \zeta
$$




$$
\begin{aligned}
\int_{0}^{\eta_{i}} & X_{8}(\eta, \zeta j) d \eta \\
& =\int_{0}^{\eta_{i}} X_{8}(\eta, 0) d \eta+\mu \int_{0}^{\zeta_{j}} \int_{0}^{\eta_{i}}\left(\kappa X_{1}-X_{6}\right) d \eta d \zeta
\end{aligned}
$$

次に, 等間隔の数值積分法の応用により, 領域 $[i, j]$ の主要点 $(i, j)$ および従属点 $(f, g)$ の諸量を用いて, これらの積分方程式を離散表示すれば, 無次元化された 断面力および変形 $X_{p},(p=1 \sim 8)$ の主要点 $(i, j)$ にお ける值 $X_{p i j}$ に関する連立方程式が次のように得られ る.

$$
\begin{aligned}
& \beta_{i i} X_{1 i j}+\mu \beta_{j j} X_{2 i j} \\
& =\sum_{k=0}^{i} \beta_{i k}\left[X_{1 k 0}-X_{1 k j}\left(1-\delta_{k i}\right)\right] \\
& \quad+\mu \sum_{l=0}^{j} \beta_{j l}\left[X_{20 l}-X_{2 i l}\left(1-\delta_{l j}\right)\right] \\
& \quad-\sum_{k=0}^{i} \sum_{l=0}^{j} \beta_{i k} \beta_{j l} \bar{q}_{k l} \\
& \beta_{i i} X_{3 i j}+\mu \beta_{j j} X_{5 i j} \\
& =\sum_{k=0}^{i} \beta_{i k}\left[X_{3 k 0}-X_{3 k j}\left(1-\delta_{k i}\right)\right] \\
& \quad+\mu \sum_{l=0}^{j} \beta_{j l}\left[X_{50 l}-X_{5 i l}\left(1-\delta_{l j}\right)\right] \\
& \quad+\mu \sum_{k=0}^{i} \sum_{l=0}^{j} \beta_{i k} \beta_{j l} X_{2 k l} \\
& \quad \ldots \ldots \ldots \ldots \ldots \ldots . . . \ldots \ldots \\
& \beta_{j j} X_{8 i}=\sum_{l=0}^{j} \beta_{j l}\left[X_{80 l}-X_{8 i l}\left(1-\delta_{l j}\right)\right] \\
& \quad+\sum_{k=0}^{i} \sum_{l=0}^{j} \beta_{i k} \beta_{j l}\left(\kappa_{k l} X_{2 k l}-X_{7 k l}\right) \\
& \beta_{i i} X_{8 i}=\sum_{k=0}^{i} \beta_{i k}\left[X_{8 k 0}-X_{8 k j}\left(1-\delta_{k i}\right)\right] \\
& \quad+\mu \sum_{k=0}^{i} \sum_{l=0}^{j} \beta_{i k} \beta_{j l}\left(\kappa_{k l} X_{1 k l}-X_{6 k l}\right)
\end{aligned}
$$

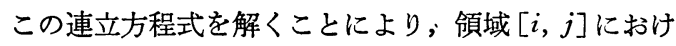
る, 主要点 $(i, j)$ の諸量 $X_{p i j}$ と境界従属点および内 部従属点, $(f, g)$, の諸量 $X_{p f g}$ との間の関係式が求め られ, 次式となる.

$$
\begin{aligned}
X_{p i j}= & \sum_{t=1}^{8}\left\{\sum_{f=0}^{i} B_{i f} A_{p t}\left[X_{t f 0}-X_{t f j}\left(1-\delta_{f i}\right)\right]\right. \\
& +\sum_{g=0}^{j} \beta_{i g} \beta_{p t}\left[X_{t o g}-X_{t i g}\left(1-\delta_{g j}\right)\right] \\
& \left.+\sum_{f=0}^{i} \sum_{g=0}^{j} \beta_{j f} \beta_{j g} C_{p t f g} X_{t f g}\left(1-\delta_{f i} \delta_{g j}\right)\right\} \\
& -\sum_{f=0}^{i} \sum_{g=0}^{j} \beta_{i f} \beta_{j g} A_{p 1} \bar{q}_{f g} \cdots \cdots \cdots \cdots \cdots(3)
\end{aligned}
$$

ここに, $p=1,2, \cdots, 8, \quad i=1,2, \cdots, m, \quad j=1,2, \cdots, n$

$\beta_{i f}=\alpha_{i f} / m, \beta_{j g}=\alpha_{j g} / n$

$\delta_{i j}$ : Kronecker's delta

$A_{p t}, B_{p t}, C_{p t f g}:$ Appendix 参照

係数 $\beta_{i f}, \beta_{j g}$ は数值積分法における重み係数である. 本論文においては, 等分割数值積分法として, Simpson
の台形公式を用いることとする．このとき，

$$
\begin{aligned}
& \alpha_{i f}= \begin{cases}0.5 & (f=0, i) \\
1 & (f \neq 0, i)\end{cases} \\
& \alpha_{j g}= \begin{cases}0.5 & (g=0, j) \\
1 & (g \neq 0, j)\end{cases}
\end{aligned}
$$

領域 $[i, j]$ を $[1,1],[1,2], \cdots[2,1],[2,2], \cdots$ と順次拉大してゆけば，ある領域の主要点は，次の，よ り拡大された領域の内部従属点となる.したがって, 最 小領域 $[1,1]$ から始めて, 順次, 領域を挔大しつつ, 各領域の主要点の諸量 $X_{p i j}$ を式 (3) により求め, こ れを次の領域の内部従属点における諸量 $X_{p f g}$ として, 式（3）の右辺に逐次代入してゆけば, 各領域の内部従 属点の諸量はすべて消去され, 結局, 任意の領域 $[i, j]$ の主要点 $(i, j)$ における諸量 $X_{p i j}$ は, この領域の境界 従属点 $(f, 0),(0, g)$ における諸量 $X_{r f 0}, X_{s 0 g},(r=$ $1,3,4,6,7,8),(s=2,3,5,6,7,8)$ のみによって 表わされることになり, 次式のように整理される.

$$
\begin{aligned}
& X_{p i j}=\sum_{d=1}^{6}\left(\sum_{f=0}^{i} a_{1 p i j f d} \cdot X_{r f 0}+\sum_{g=0}^{j} a_{2 p i j g d} \cdot X_{s 0 g}\right) \\
& +q_{p i j}
\end{aligned}
$$

ここに，

$$
\begin{aligned}
& a_{h p i j u d}=\sum_{t=1}^{8}\left\{\sum_{k=0}^{i} \beta_{i k} A_{p t}\left[a_{h t k 0 u d}-a_{h t k j u d}\left(1-\delta_{k i}\right)\right]\right. \\
& +\sum_{l=0}^{j} \beta_{j l} B_{p t}\left[a_{h t 0 l u d}-a_{h t i l u d}\left(1-\delta_{l j}\right)\right] \\
& \left.+\sum_{k=0}^{i} \sum_{l=0}^{j} \beta_{i k} \beta_{j l} C_{p t k l} a_{h t k l u d}\left(1-\delta_{k i} \delta_{l j}\right)\right\} \\
& q_{p i j}=\sum_{t=1}^{8}\left\{\sum_{k=0}^{i} \beta_{i k} A_{p t}\left[q_{t k 0}-q_{t k j}\left(1-\delta_{k i}\right)\right]\right. \\
& +\sum_{l=0}^{j} \beta_{j l} B_{p t}\left[q_{t 0 l}-q_{t i l}\left(1-\delta_{l j}\right)\right] \\
& \left.+\sum_{k=0}^{i} \sum_{l=0}^{j} \beta_{i k} \beta_{j l} C_{p t k l} q_{t k l}\left(1-\delta_{k i} \delta_{l j}\right)\right\} \\
& -\sum_{k=0}^{i} \sum_{l=0}^{j} \beta_{i k} \beta_{j l} A_{p_{1}} \bar{q}_{k l} \\
& p=1 \sim 8, i=1 \sim m, j=1 \sim n, f=0 \sim i, g=0 \sim j, \\
& d=1 \sim 6, h=1,2, u=f(h=1 \text { のとき) or } g(h \\
& =2 \text { のとき) } \\
& a_{1 \text { rioid }}=1, a_{2 s 0 j j d}=1 \\
& a_{110 j 01}=\frac{\kappa_{00}}{\kappa_{0 j}} \bar{\alpha}_{j}, \quad a_{22 i 001}=\frac{\kappa_{00}}{\kappa_{i 0}} \bar{\alpha}_{i} \\
& a_{140 j 03}=\frac{\bar{D}_{00}}{\bar{D}_{0 j}} \bar{\alpha}_{j}, \quad a_{25 i 003}=\frac{\bar{D}_{00}}{\bar{D}_{i 0}} \bar{\alpha}_{i} \\
& a_{12 i 0 k 5}=\frac{1}{\kappa_{i 0}} \bar{\beta}_{i k}, \quad a_{210 j l 4}=\frac{1}{\kappa_{0 j}} \bar{\beta}_{j l} \\
& a_{15 i 0 k 3}=\nu \frac{\bar{D}_{00}}{\bar{D}_{i 0}} \bar{\beta}_{i k}, a_{240 j l 3}=\nu \frac{\bar{D}_{0 l}}{\bar{D}_{0 j}} \bar{\beta}_{j l} \\
& a_{12 i 0 k 6}=\frac{1}{\kappa_{i 0}} \bar{\gamma}_{i k}, \quad a_{210 j l 6}=\frac{1}{\mu \kappa_{0 j}} \bar{\gamma}_{j l} \\
& a_{15 i 0 k 5}=\frac{1}{\bar{D}_{i 0}} \bar{\gamma}_{i k}, \quad a_{240 j l 4}=\frac{1}{\mu D_{0 j}} \bar{\gamma}_{j l}
\end{aligned}
$$




$$
\begin{aligned}
& \bar{\alpha}_{i}=(-1)^{i}, \quad \bar{\beta}_{i k}=\delta_{i k}+(-1)^{i+1} \cdot \delta_{0 k} \\
& \bar{\gamma}_{i k}=\frac{4 m(-1)^{i+k}}{1+\delta_{i k}+\delta_{0 k}}, \quad \bar{D}_{i 0}=\frac{D_{0}}{D_{i 0}} \\
& r=d+\delta_{2 f}+\delta_{3 f}+2\left(\delta_{4 f}+\delta_{5} f+\delta_{6 f}\right) \\
& s=d+\delta_{1 f}+\delta_{2 f}+2\left(\delta_{3 f}+\delta_{4}+\delta_{5 f}+\delta_{6 f}\right)
\end{aligned}
$$

式 (4) は, 変厚矩形板の縦横の等分割線の交点におけ る, 基礎微分方程式 $(2 \cdot \mathrm{a}) \sim(2 \cdot \mathrm{h})$ の離散表示された近 似解である. この解式中に含まれる境界従属点の 6 個ず つの諸量 $X_{r f 0}, X_{s 0 g}$ はいわゆる積分定数であり, 境界 条件によって決定されるべきものである．また，任意 の領域 $[i, j]$ の主要点 $(i, j)$ における諸量 $X_{p i j}$ を, こ の領域の境界従属点 $(f, 0),(0, g)$ における諸量 $X_{r f 0}$, $X_{s 0 g}$ に関係ゔける要素 $a_{h p i j u d}$ は, 伝達マトリックス 法におけるいわゆる伝達マトリックスに相当するもので ある. 近似解 (4) に基づいて得られる平板の数值解の 収束性および精度に関しては，5．において検討するこ ととする。

\section{4. 積分定数と境界条件}

基礎微分方程式 $(2 \cdot \mathrm{a}) \sim(2 \cdot \mathrm{h})$ の近似解（4）に含ま れる積分定数 $X_{r f 0}$ および $X_{s 0 g}$ は, 具体的には, それ ぞれ, 平板の $\zeta=0$ および $\eta=0$ なる辺上の等分割点 $(f, 0)$ および $(0, g)$ における断面力および変形を表わ す. 各分割点において 6 個ずつの積分定数が存在する が, 平板の境界辺の支持条件に応じて, これらの中のい ずれか 3 個の積分定数は既知となる. 残りの 3 個の積分 定数の值は対辺の境界条件によって決定される.

Fig. 2 Fig. 6 に, 5 種の異なる境界条件をもつ平 板の積分定数と境界条件を示す.これらの各図におい

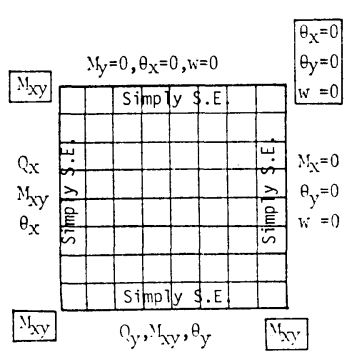

(a)

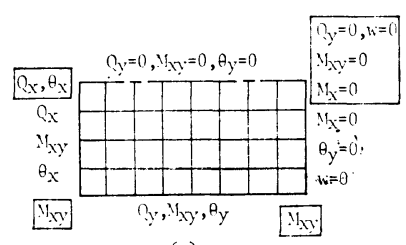

(c)

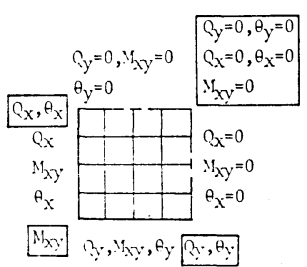

ib)

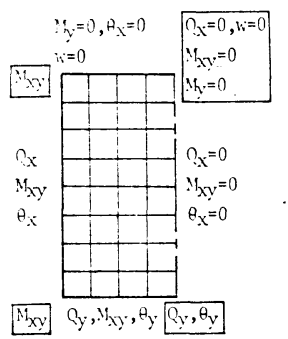

(d)
Fig. 2 Integral Constants and Boundary Conditions of Plate with Four Simply Supported Edges. て，（a）図は平板全体を対象とした場合である。(d) 図 および，(c）図は，それぞれ，左右または上下の 1 軸対 称性をもつ平板の $1 / 2$ 部分を対象とした場合である.ま た，(b) 図は，左右および上下の 2 軸対称性をもつ平板 の $1 / 4$ 部分を対象とした場合である. 各図において，隅 角部の分割点の積分定数および境界条件は $\square$ で囲まれ ている. なお, 隅角点における積分定数および境界条件 は，その隅角点において交差する 2 境界辺上での諸量間 の関係を考慮して定められる.たとえば，Fig. 2 (a) に 示す四辺単純支持板の, $x=0, y=0$ なる隅角点におけ る積分定数は次のようになる. すなわち， $x=0$ なる境 界辺上においては, $M_{x}=\theta_{y}=w=0$ であり,また, $y=0$

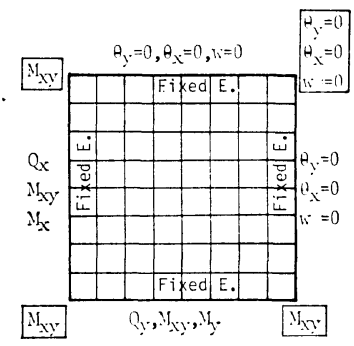

(a)

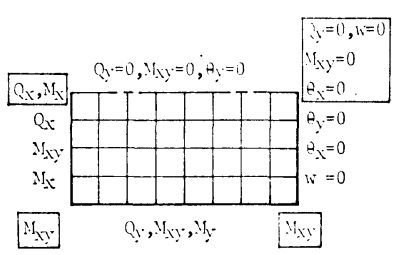

(c)

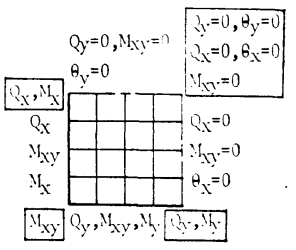

(b)

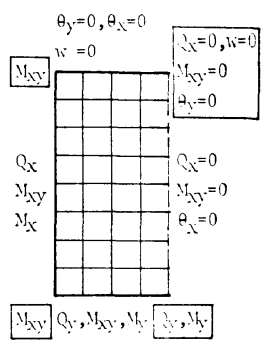

(d)
Fig. 3 Integral Constants and Boundary Conditions of Plate with Four Fixed Edges.

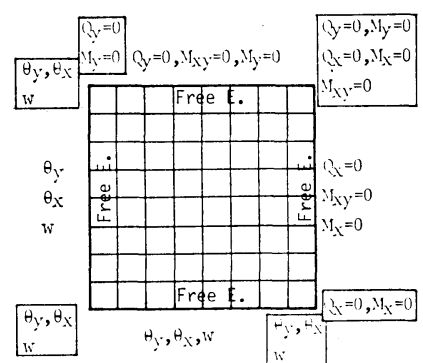

(a)

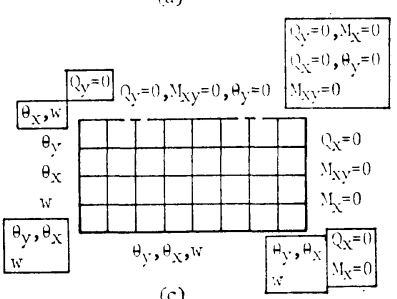

(c)

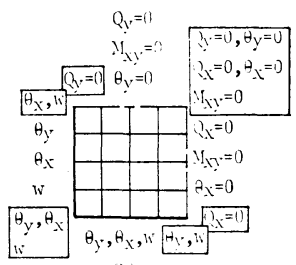

(b)

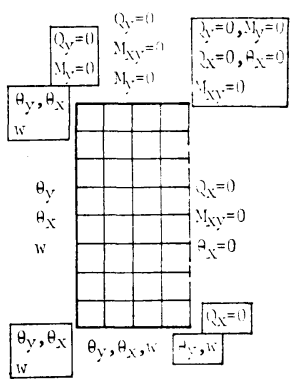

(d)
Fig. 4 Integral Constants and Boundary Conditions of Plate with Four Free Edges. 


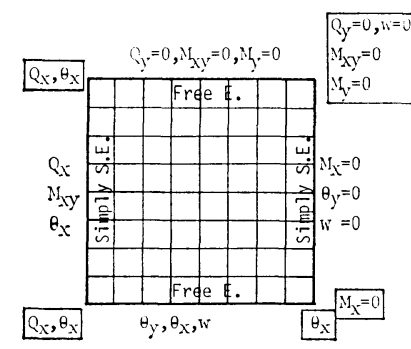

(a)

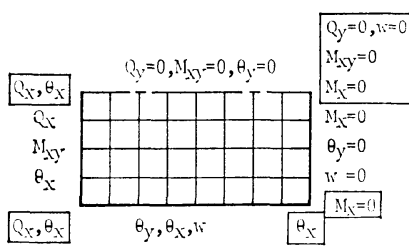

(c)

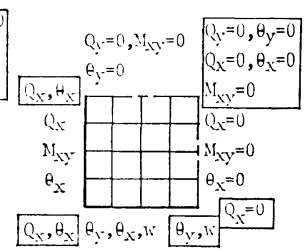

(b)

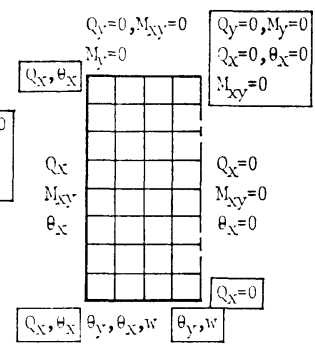

(d)

Fig. 5 Integral Constants and Boundary Conditions of Plate with Two Opposite Edges Simply Supported and the Other Two Edges Free.

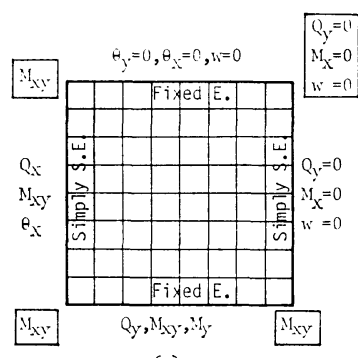

(a)

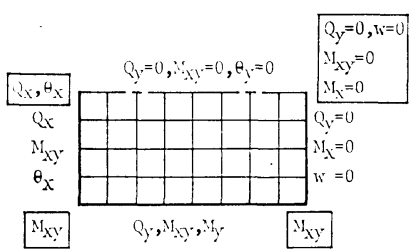

(c)

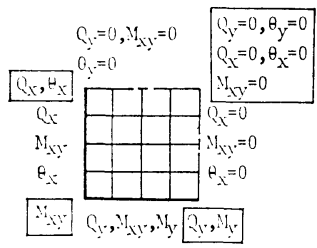

(b)

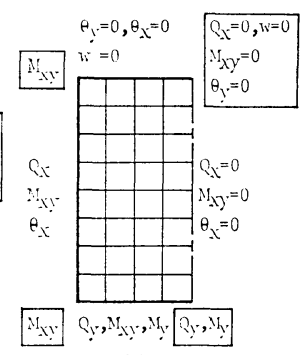

(d)

Fig. 6 Integral Constants and Boundary Conditions of Plate with Two Opposite Edges Simply Supported and the Other Two Edges Fixed.

なる境界辺上においては, $M_{y}=\theta_{x}=w=0$ であるから， 両境界辺の交点である $x=0, y=0$ なる隅角点におい ては，これらすべてが満足されなければならないので

$$
M_{y}=0, M_{x}=0, \theta_{y}=0, \theta_{x}=0, w=0
$$

となる.また, 境界辺 $y=0$ 上においては, $w=0$, であ ることから, 式 $(1 \cdot \mathrm{g})$ より, $\partial w / \partial x=Q_{x} / G t_{s}-\theta_{x}=0$, となり, $Q_{x} / G t_{s}=\theta_{x}$, なる関係が得られるが, この辺上 においては, $\theta_{x}=0$, であるから，また， $Q_{x}=0$ ともな る.したがって, 境界辺 $y=0$ 上の端点である $y=0$, $x=0$, の隅角点においては

$$
Q_{x}=0
$$

となる. 同様にして, 境界辺 $x=0$ 上においては, $w=$ 0 であることから, 式 $(1 \cdot \mathrm{h})$ より, 隅角点 $x=0, y=0$ において

$$
Q_{y}=0
$$

となり, 結局, この隅角点における未知の積分定数とし ては, $M_{x y}$ のみが残ることになる.

また，Fig. 2 (a) に示す四辺単純支持板の， $x=a, y$ $=b$ なる隅角点に打境界条件は次のようになる。す なわち, $x=a$ なる境界辺上においては, $M_{x}=\theta_{y}=w=$ 0 ，であり，また， $y=b$ なる境界辺上においては， $M_{y}$ $=\theta_{x}=w=0$ であるゆえ, 両境界辺の交点である, $x=a$, $y=b$, なる隅角点においては, これらすべてが満足され なければならないので，

$$
M_{y}=0, M_{x}=0, \theta_{y}=0, \theta_{x}=0, w=0
$$

となる. 一方, 境界辺 $y=b$, および $x=a$ 上において は式 (1・d) および (1・e) より

境界辺 $y=b$ 上において

$$
\frac{\partial \theta_{x}}{\partial x}=\frac{1}{\left(1-\nu^{2}\right) D}\left(M_{x}-\nu M_{y}\right)
$$

境界辺 $x=a$ 上において

$$
\frac{\partial \theta_{y}}{\partial y}=\frac{1}{\left(1-\nu^{2}\right) D}\left(M_{y}-\nu M_{x}\right)
$$

なる関係が成立する。したがって，本例のように，境界 辺 $y=b$ および $x=a$ 上において，それぞれ， $\theta_{x}=0$ お よび $\theta_{y}=0$ の場合には, $\partial \theta_{x} / \partial x=0$, および $\partial \theta_{y} / \partial y=$ 0 であるから, 境界辺 $y=b$ 上においては, $M_{x}=\nu M_{y}$ となり，また，境界辺 $x=a$ 上においては， $M_{y}=\nu M_{x}$ となる. したがって, 両境界辺の交点である $x=a, y=$ $b$ の隅角点においては, 必然的に $M_{x}=M_{y}=0$ となる. よって，この隅角点における独立な境界条件は

$$
\theta_{y}=0, \theta_{x}=0, w=0
$$

の 3 条件となる.

\section{5. 数値解の収束性および精度}

本解析法による矩形板の数值解の収束性および精度を 検討するために, 既往の近似解法による解析結果との比 較および解析解との比較を行う. なお, 数值解の比較に 用いた既往の解析結果は，いずれも，せん断変形の影響 を無視した Kirchhoff の薄板曲げ理論に基づいている. 一方, 本論文に用いた基礎式 $(1 \cdot \mathrm{a}) \sim(1 \cdot \mathrm{h})$ は, せん断 変形の影響を考慮した Reissner の平板曲げ理論に基づ くものである.したがって，これら両者の比較のため に, 本法における平板の解析においては, せん断変形の 影響を十分に無視できる薄板を取り扱うこととし, 板厚 $h$ と辺長 $a$ の比を $h / a=0.01$ とする. 
Table 1 Convergency of Numerical Solutions of Plate with Four Simply Supported Edges under Uniform Load $(\nu=0.3)$.

\begin{tabular}{r|c|c|c|c|c|c|c|c}
\hline \multirow{2}{*}{$m$} & \multirow{2}{*}{$Q_{y} / q a$} & \multicolumn{2}{|c|}{$M_{x y} / q a^{2}$} & \multicolumn{2}{c|}{$M_{x} / q a^{2}$} & \multicolumn{3}{|c}{$w / q a^{4} / D$} \\
\cline { 3 - 7 } \cline { 5 - 8 } & & Author & Kurata & Author & Kurata & Author & Kurata & Kubo \\
\hline 4 & 0.334 & -0.0340 & -0.0308 & 0.0542 & 0.0472 & 0.00412 & 0.00400 & 0.00394 \\
8 & 0.336 & -0.0328 & -0.0319 & 0.0492 & 0.0479 & 0.00408 & 0.00406 & 0.00407 \\
12 & 0.337 & -0.0325 & -0.0321 & 0.0484 & 0.0479 & 0.00407 & 0.00406 & 0.00408 \\
16 & 0.337 & -0.0325 & -0.0323 & 0.0482 & 0.0499 & 0.00407 & 0.00406 & 0.00408 \\
20 & 0.338 & -0.0325 & -0.0324 & 0.0481 & 0.0479 & 0.00407 & 0.00406 & \\
\hline N.A.S. & 0.338 & \multicolumn{2}{|c|}{-0.0325} & \multicolumn{2}{|c|}{0.0479} & \multicolumn{3}{|c|}{0.00406} \\
\hline
\end{tabular}

\section{(1) 等 厚 板}

はじめに，等厚板に関して，本解析 法による数值解の収束性および精度を 明らかにするために，等分布荷重を満 載する, 四辺単純支持板, 四辺固定 板, 対辺単純支持他対辺固定支持板, および，中央点に集中荷重を受ける四 辺単純支持板について，断面力および 変形の解析を行った. これらの結果 を，文献 2)，5）の結果および既往の N.A.S. : Navier's Analytical Solution

Table 2 Convergency of Numerical Solutions of Plate with Four Fixed Edges under Uniform Load $(\nu=$ $0.3)$.

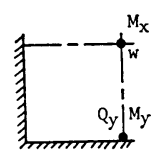

\begin{tabular}{r|c|c|c|c|c|c|c}
\hline \multirow{2}{*}{$m$} & \multirow{2}{*}{$Q_{y} / q a$} & \multicolumn{2}{|c|}{$M_{x} / q a^{2}$} & \multicolumn{2}{c|}{$M_{y} / q a^{2}$} & \multicolumn{2}{c}{$w / q a^{4} / D$} \\
\cline { 3 - 7 } & & Author & Kurata & Author & Kurata & Author & Kurata \\
\hline 4 & 0.664 & 0.0272 & 0.0227 & -0.0623 & -0.0510 & 0.00130 & 0.00126 \\
8 & 0.452 & 0.0248 & 0.0226 & -0.0525 & -0.0515 & 0.00127 & 0.00127 \\
12 & 0.437 & 0.0238 & 0.0229 & -0.0519 & -0.0515 & 0.00127 & 0.00127 \\
16 & 0.440 & 0.0234 & 0.0229 & -0.0517 & -0.051 .9 & 0.00127 & 0.00127 \\
20 & 0.440 & 0.0232 & 0.0230 & -0.0515 & -0.0539 & 0.00127 & 0.00127 \\
\hline T.A.S. & \multicolumn{3}{|c|}{0.0231} & \multicolumn{2}{|c|}{-0.0513} & \multicolumn{2}{c}{0.00126} \\
\hline
\end{tabular}

T.A.S. : Timoshenko's Analytical Solution

Table 3 Convergency of Numerical Solutions of Plate with Two Opposite Edges Simply Supported and the Othe Two Edges Fixed under Uniform Load $(\nu=0.3)$.

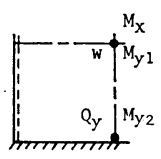

\begin{tabular}{c|c|c|c|c|c}
\hline$m$ & $Q_{y} / q a$ & $M_{x} / q a^{2}$ & $M_{y_{1}} / q a^{2}$ & $M_{y_{2}} / q a^{2}$ & $w / q a^{4} / D$ \\
\hline 4 & 0.474 & 0.0280 & 0.0484 & -0.0737 & 0.00184 \\
8 & 0.512 & 0.0251 & 0.0359 & -0.0711 & 0.00190 \\
12 & 0.517 & 0.0247 & 0.0343 & -0.0704 & 0.00191 \\
16 & 0.516 & 0.0246 & 0.0338 & -0.0701 & 0.00191 \\
20 & 0.516 & 0.0245 & 0.0336 & -0.0700 & 0.00191 \\
\hline T.A.S. & & 0.0244 & 0.0332 & -0.0697 & 0.00192 \\
\hline
\end{tabular}

T.A.S. : Timoshenko's Analytical Solution

Table 4 Convergency of Numerical Solutions of Plate with Four Simply Supported Edges under a Concentrated Load Applied at the Center $(\nu=0.3)$.

\begin{tabular}{c|c|c|c|c|c|c|c}
\hline$m$ & \multirow{2}{*}{$Q_{y} / P / a$} & \multirow{2}{*}{$M_{x y} / P$} & \multicolumn{2}{|c|}{$M_{x} / P$} & \multirow{2}{*}{$M_{y} / P$} & \multicolumn{2}{|c}{$w / P a^{2} / D$} \\
\cline { 4 - 7 } & & & Author & Kurata & & Author & Kurata \\
\hline 4 & 0.333 & -0.0632 & - & 0.170 & - & 0.0083 & 0.0111 \\
8 & 0.387 & -0.0623 & - & 0.193 & - & 0.0103 & 0.0113 \\
12 & 0.402 & -0.0615 & 0.160 & 0.205 & 0.187 & 0.0110 & 0.0114 \\
16 & 0.408 & -0.0612 & 0.153 & 0.210 & 0.191 & 0.0112 & 0.0115 \\
20 & 0.411 & -0.0611 & 0.148 & 0.211 & 0.193 & 0.0114 & 0.0115 \\
24 & 0.413 & -0.0611 & 0.147 & - & 0.194 & 0.0114 & - \\
\hline T.A.S. & & \multicolumn{3}{|c|}{0.147} & 0.202 & \multicolumn{2}{|c|}{0.0116} \\
\hline
\end{tabular}

T.A.S. : Timoshenko's Analytical Solution
解析解とともに，それぞれ Table 1 Table 4 に示す. 示された諸量は, 表中図の各点の断面 力および変形である.

いずれの解析においても，本解析法に基ゔく 断面力および変形の数值解は, 分割数 $m$ の増 加とともに，一様に収束することが示されてい る. また, 8〜12 程度の比較的粗い分割のもと でも十分に実用性のある解が得られている.

\section{(2) 変 厚 板}

次に, 本解析法による変厚板の数值解の精度 を明らかにするために，Fig. 7 に示すような， 一方向にのみ板厚が直線的に変化する変厚板に 関して, 断面力および変形の解析を行った.こ

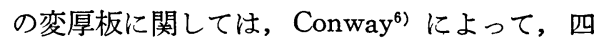
辺単純支持の場合および対辺単純支持他対辺固 定支持の場合について解が求められている.こ れらの結果を, Fig. 7 の $y=a / 2$ 断面上のせ

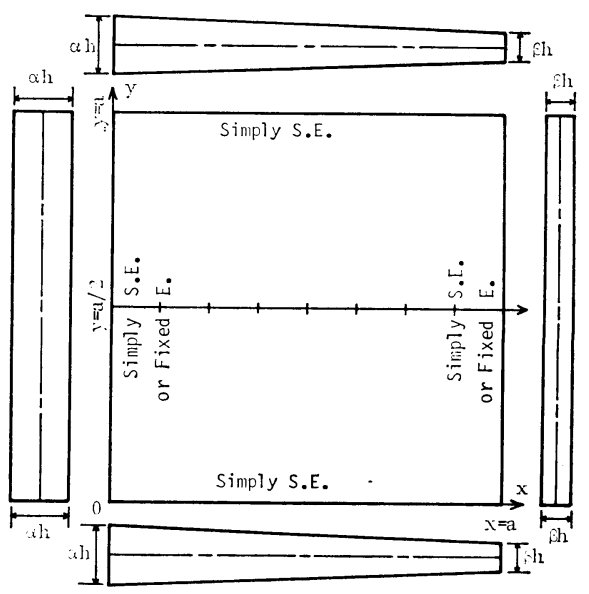

Case $1: \alpha=1.2, \beta=0.8$

Case 2: $\alpha=1.1, \beta=0.9$ $(v=0.25)$

Fig. 7 Rectangular Plate with Varying Thickness. 


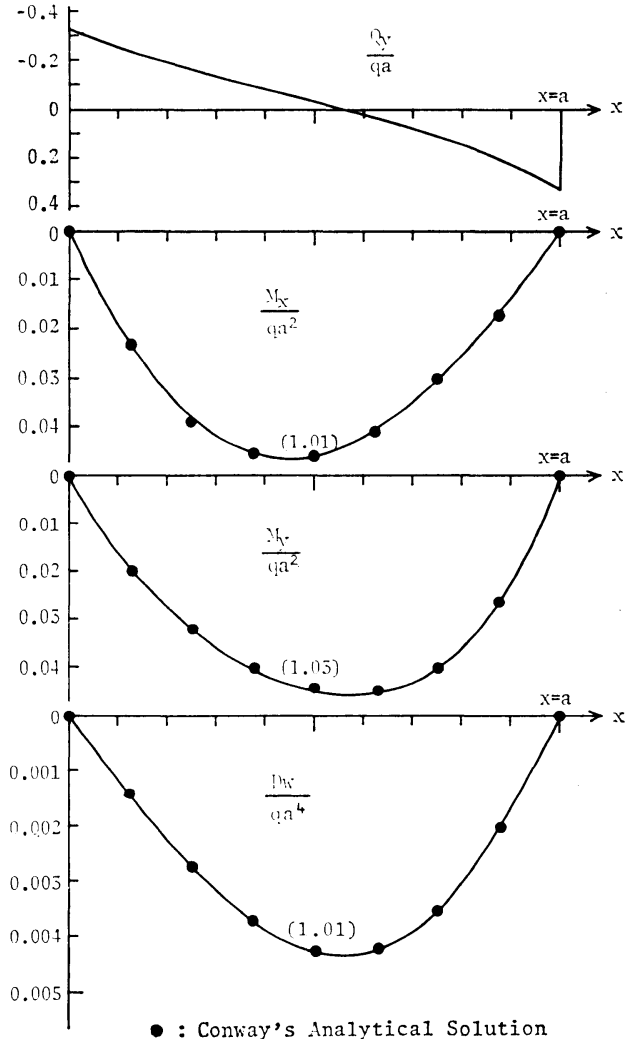

Case I

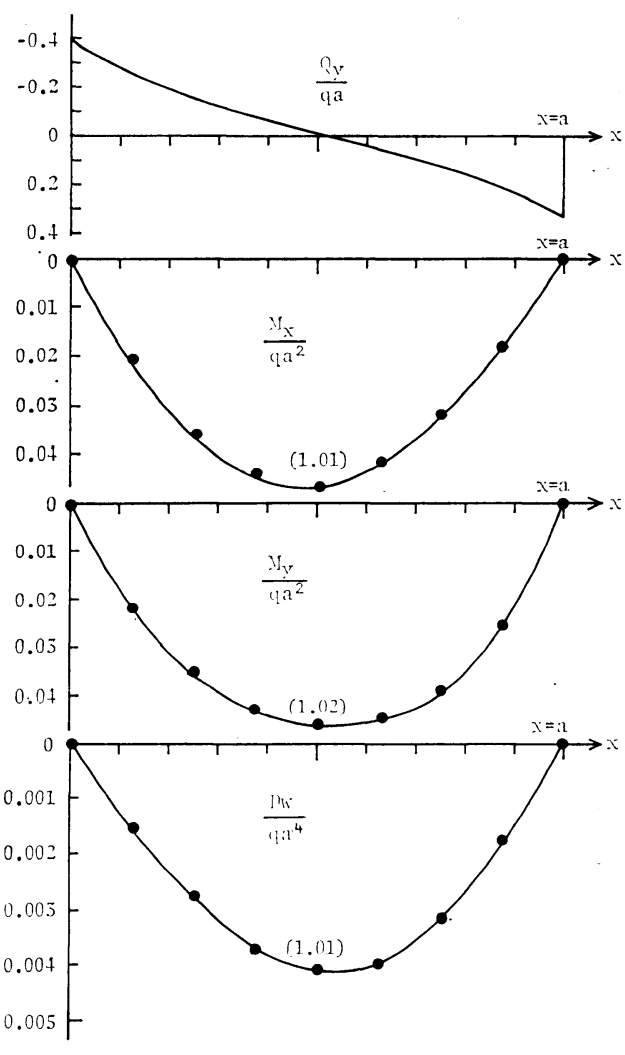

Casc 2

(a)

(b)

Fig. 8 Shearing Force, Bending Moment and Deflection of Plate with Varying Thickness.

ん断力, 曲げモーメントおよびたわみに関して，Fig. 8 (a)，(b) および Fig. 9 (a)，(b) に示す. なお，本解 析における分割数 $m$ は 8 である. 図中（）内に記入 の数値は, 本解析法による近似解の Conway の解析解 に対する比である.これらの諸量は, Table 1 および Table 3 に示された，等厚板の $m=8$ の場合の近似解 の解析解に対する比とほぼ同等となっている.このこと から，本例に示された程度の板厚変化を有する変厚板 は, 同一分割数のもとで, 等厚板と同程度の精度で解析 できるものと判断される.

\section{6. 結語}

微分方程式の積分方程式への変換と積分方程式の近似 解法の応用とにより, 変厚矩形板の基礎微分方程式の解 析的近似解を求め, これに基づく変厚矩形板の一般的な 解法を提示した．数值解析の結果から，本解法による数 值解は一様な収束性をもつこと，また，比較的粗い分割 による解析においても実用上十分の精度をもつ解が得ら
れることなどが確認された.

本解法によれば, 荷重の分布状態や板厚, 板剛度の場 所的変化が不規則で関数表示できない場合でも，矩形板 の縦横の等分割線の交点におけるこれら諸量の值が与え られれば，諸量が規則的な場合とまったく同様に解析す ることができる.

また, 本解法は, 矩形板以外の任意の四辺形板の解析 や平板の弾塑性解析，大変形解析などへの応用も容易 で，これらについては改めて報告の予定である.

\section{Appendix}

$$
\begin{aligned}
& A_{p 1}=\gamma_{p 1}, A_{p 2}=0, A_{p 3}=\gamma_{p 2}, A_{p 4}=\gamma_{p 3} \\
& A_{p 5}=0, A_{p 6}=\gamma_{p 4}+\nu r_{p 5}, A_{p 7}=\gamma_{p 6}, A_{p 8}=\gamma_{p 7} \\
& B_{p_{1}}=0, B_{p_{2}}=\mu r_{p_{1}}, B_{p_{3}}=\mu r_{p 3}, B_{p^{4}}=0 \\
& B_{p 5}=\mu r_{p_{2}}, B_{p 6}=\mu r_{p 6}, B_{p 7}=\mu\left(\nu r_{p^{4}}+r_{p 5}\right) \\
& B_{p 8}=r_{p 8} \\
& C_{p_{1} k l}=\mu\left(\gamma_{p_{3}}+\kappa_{k l} \gamma_{p_{7}}\right), C_{p_{2} k l}=\mu \gamma_{p_{2}}+\kappa_{k l} \gamma_{p 8} \\
& C_{p 3 k l}=J_{k l} \gamma_{p 6}, C_{p 4 k l}=I_{k l} \gamma_{p 4}, C_{p 5 k l}=I_{k l} \gamma_{p 5}
\end{aligned}
$$



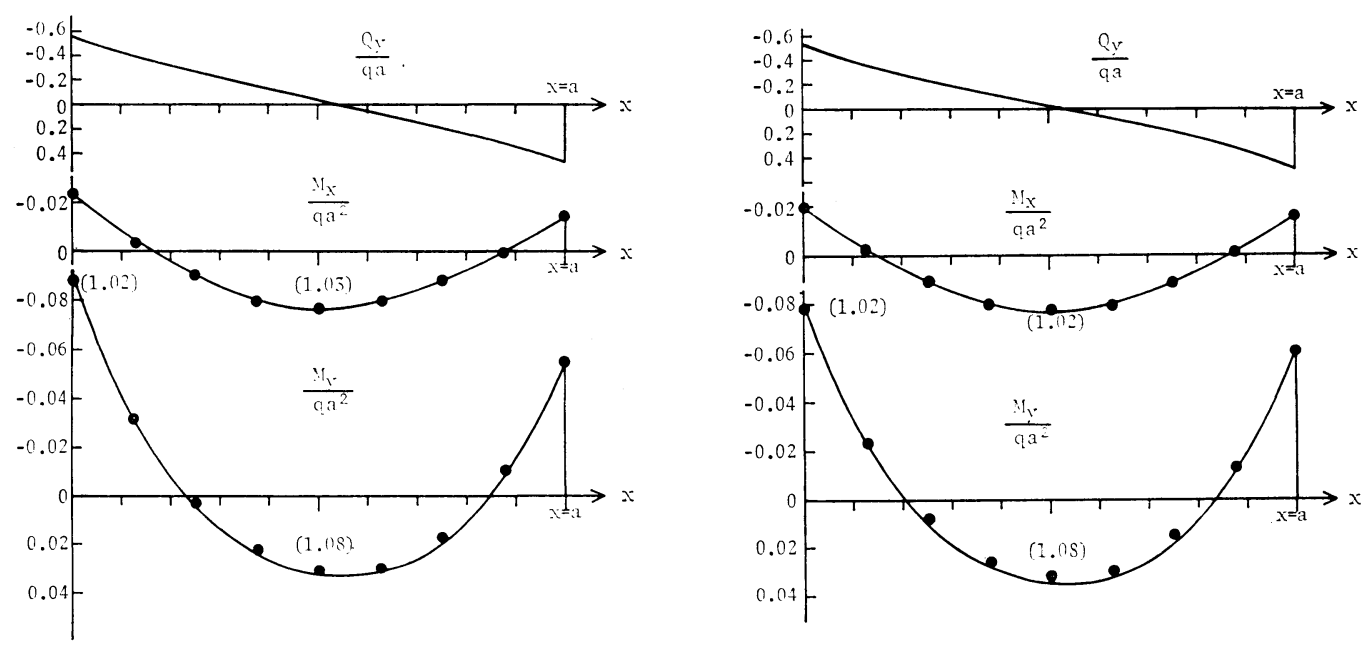

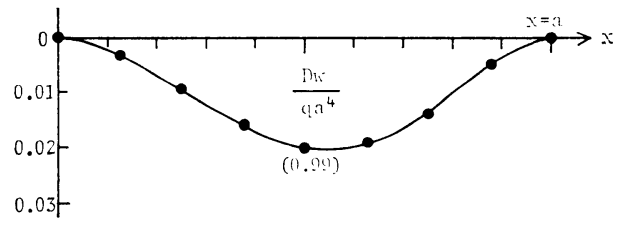

Case 1

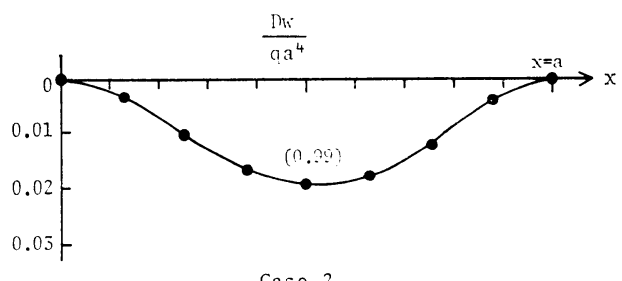

(b)

Fig. 9 Shearing Force, Bending Moment and Deflection of Plate with Varying Thickness.

$C_{p 6 k l}=-\mu r_{p 7}, C_{p 7 k l}=-r_{p 8}, C_{p 8 k l}=0$

$\left[\gamma_{p t}\right]=\left[\bar{\gamma}_{p t}\right]^{-1}$

$\bar{\gamma}_{11}=\beta_{i i}, \bar{\gamma}_{12}=\mu \beta_{j j}, \bar{\gamma}_{22}=-\mu \beta_{i j}, \bar{\gamma}_{23}=\beta_{i i}$

$\bar{\gamma}_{25}=\mu \beta_{j j}, \bar{\gamma}_{31}=-\mu \beta_{i j}, \bar{\gamma}_{33}=\mu \beta_{j j}, \bar{\gamma}_{34}=\beta_{i i}$

$\bar{\gamma}_{44}=-I_{i j} \beta_{i j}, \bar{\gamma}_{46}=\beta_{i i}, \bar{\gamma}_{47}=\mu \nu \beta_{j j}, \bar{\gamma}_{55}=-I_{i j} \beta_{i j}$

$\bar{\gamma}_{56}=\nu \beta_{i i}, \bar{\gamma}_{57}=\mu \beta_{j j}, \bar{\gamma}_{63}=-J_{i j} \beta_{i j}, \bar{\gamma}_{66}=\mu \beta_{j j}$

$\bar{\gamma}_{67}=\beta_{i i}, \bar{\gamma}_{71}=-\mu \kappa_{i j} \beta_{i j}, \bar{\gamma}_{76}=\mu \beta_{i j}, \bar{\gamma}_{78}=\beta_{i i}$

$\bar{\gamma}_{82}=-\kappa_{i j} \beta_{i j}, \bar{\gamma}_{87}=\beta_{i j}, \bar{\gamma}_{88}=\beta_{j j}$

$\beta_{i j}=\beta_{i i} \cdot \beta_{j j}$

参 考 文 献

1）梶田建夫・成岡昌夫 : 変断面長方形板の曲げ, および, 振
動に対する有限要素法の応用, 土木学会論文報告集, 第 161 号, 1969.

2) 倉田宗章 - 谷平 勉 : 変厚四辺形板の曲げ解析, 土木学 会論文報告集, 第 195 号, 1971 .

3）中川建治 : 4 辺単純支持変厚板の曲げたわみに 関する研 究, 土木学会論文報告集, 第 249 号, 1976.

4) Fan Jia-rang : Plates of Varying Thickness with Four Simply Supported Edges, Proc. ASCE, Vol. 108, EM $1,1982$.

5） 久保慶三郎・吉田 裕 : 任意形状の平板曲げの数值解析 法, 土木学会論文報告集, 第 167 号, 1969 .

6) Petrina, P. and H.D. Conway : Deflection and Moment Data for Rectangular Plates of Variable Thickness, Jour. Appl. Mech., Vol. 39, 1972.

(1982.12.13 - 受付) 